\title{
Resistência de genótipos de feijão-de-corda ao pulgão-preto
}

\author{
Jefté Ferreira da Silva(1) e Ervino Bleicher ${ }^{(1)}$ \\ (1)Universidade Federal do Ceará, Avenida Mister Hull, s/no, Pici, CEP 60455-760 Fortaleza, CE. E-mail: jefteferreira@gmail.com, \\ ervino@ufc.br.
}

\begin{abstract}
Resumo - O objetivo deste trabalho foi avaliar a resistência de genótipos de feijão-de-corda (Vigna unguiculata) ao pulgão-preto (Aphis craccivora). Foram realizados experimentos com e sem chance de escolha em casa de vegetação, na Universidade Federal do Ceará. O delineamento utilizado foi o de blocos ao acaso com vinte tratamentos, representados pelos genótipos 421-07-44, Chumbinho, Zebu, EPACE 10, Frade Preto, Inhumã, João Paulo II, Manteiguinha, Maranhão, Pitiúba, Quarenta Dias, Seridó, Sete Semanas, TVu 1037, TVu 1888, TVu 310, TVu 36, TVu 408 $\mathrm{P}_{2}$, TVu 410 e VITA 7. Verificou-se que TVu 408 $\mathrm{P}_{2}$, TVu 1037 e TVu 410 foram preteridos por adultos e ninfas do pulgão-preto, em ambos experimentos. Os genótipos TVu $408 \mathrm{P}_{2}, \mathrm{TVu} 410$, $\mathrm{TVu} 36$ e TVu 1037 apresentam resistência provavelmente do tipo antibiose ou antixenose. O genótipo 421-07-44 mostrou-se suscetível ao pulgão-preto.
\end{abstract}

Termos para indexação: Aphis craccivora, Vigna unguiculata, preferência alimentar, oviposição.

\section{Resistance of cowpea genotypes to the cowpea black aphid}

\begin{abstract}
The objective of this work was to evaluate cowpea (Vigna unguiculata) genotypes for resistance to the black aphid (Aphis craccivora). Experiments, with and without choice, were performed in the greenhouse, at the Universidade Federal do Ceará, Fortaleza, Brazil. The experimental design was a randomized complete block with twenty treatments represented by the genotypes 421-07-44, Chumbinho, Zebu, EPACE 10, Frade Preto, Inhumã, João Paulo II, Manteiguinha Maranhão, Pitiúba, Quarenta Dias, Seridó, Sete Semanas, TVu 1037, TVu 1888, TVu 310, TVu 36, TVu 408 $\mathrm{P}_{2}$, TVu 410 and VITA 7. The genotypes TVu 408 $\mathrm{P}_{2}, \mathrm{TVu} 1037$ and $\mathrm{TVu} 410$ were less preferred by adults and nymphs of the black aphid in both assays. The genotypes $\mathrm{TVu} 408 \mathrm{P}_{2}$, $\mathrm{TVu} 410, \mathrm{TVu} 36$ and TVu 1037 probably presented antibiosis or antixenosis resistance. The genotype 421-07-44 was susceptible the black aphid.
\end{abstract}

Index terms: Aphis craccivora, Vigna unguiculata, feeding preference, oviposition.

\section{Introdução}

O cultivo do feijão-de-corda [Vigna unguiculata (L.) Walp.] é amplamente distribuído nas regiões tropicais e subtropicais do mundo, e essa leguminosa é um alimento básico para a população dessas regiões. No Brasil, é largamente cultivado por pequenos produtores do Semiárido Nordestino e de regiões isoladas da Amazônia, onde é a principal cultura de subsistência (Freire Filho et al., 2005; Teófilo et al., 2008).

Várias espécies de insetos provocam danos à cultura do feijão-de-corda e prejuízos aos produtores. Entre esses insetos, o pulgão-preto, [Aphis craccivora Koch, 1854 (Hemiptera: Aphididae)] destaca-se como praga principal (Pettersson et al., 1998; Agele et al., 2006). Esse hemíptero ocorre em todo o Nordeste brasileiro, sobretudo no período seco, em cultivos de feijão-de-corda sob irrigação (Silva et al., 2005).

$\mathrm{O}$ inseto infesta inicialmente as plântulas e, à medida que a planta se desenvolve, pode infestar flores e vagens (Berberet et al., 2009). A ação de sucção dos pulgões provoca o encarquilhamento das folhas e deformação dos brotos (Silva et al., 2005). Com o decorrer do tempo e com o aumento da população de pulgões, as plantas atacadas ficam debilitadas por causa da quantidade de seiva retirada e de toxinas injetadas. Além disso, A. craccivora é um eficiente transmissor de vírus, entre eles o Cowpea aphidborne mosaic virus (CABMV) (Kitajima et al., 2008).

Entre as formas de controle de A. craccivora, destacam-se os controles químico (Das et al., 2008), cultural e biológico (Omkar et al., 2005; Rakhshani et al., 2005), além do uso de plantas resistentes (Hall et al., 2003). Essa última alternativa é considerada

Pesq. agropec. bras., Brasília, v.45, n.10, p.1089-1094, out. 2010 
de maior importância, pois diminui o uso de defensivos agrícolas e evita o surgimento de resistência do inseto a esses produtos. Identificações de fontes de resistência genética têm sido realizadas para se obter materiais genéticos a serem utilizados no desenvolvimento de plantas resistentes ao pulgão-preto. Os genótipos de Tropical Vigna unguiculata (TVu) TVu 310, TVu 801 e $\mathrm{TVu} 408 \mathrm{P}_{2}$ parecem ser imunes à infestação por A. craccivora, pois a fecundidade desses pulgões nesses genótipos, dez dias após a infestação, inexiste, enquanto, nas linhas suscetíveis, o número de indivíduos chega a ser de 300 por planta (Singh, 1987). Em estudo em casa de vegetação na Nigéria, Ofuya (1988) concluiu que os genótipos TVu 3000, TVu 2896 e TVu 1037 apresentam resistência do tipo antibiose, em razão da alta mortalidade de ninfas e das reduzidas taxas de fecundidade e longevidade observadas, em comparação ao genótipo mais suscetível, H113-1.

No Brasil, Moraes \& Bleicher (2007) avaliaram a resistência de variedades de feijão-de-corda ao pulgão A. craccivora e relataram que os genótipos EPACE 10 e Patativa foram preteridos, tanto para alimentação quanto para oviposição, e que EPACE 11, 'Pitiúba' e 'Pingo de Ouro' foram preferidos pelo inseto, em condição de casa de vegetação. Esses autores, em um segundo ensaio com outros genótipos, concluíram que BR-10 Piauí, BR-12 Canindé, BR-14 Mulato e BR-17 Gurguéia não diferiram estatisticamente do suscetível Pitiúba, sendo todos esses materiais preferidos pelo pulgão.

O objetivo deste trabalho foi avaliar genótipos de feijão-de-corda quanto à resistência ao pulgão-preto.

\section{Material e Métodos}

O trabalho constou de dois ensaios conduzidos no Campus do Pici, da Universidade Federal do Ceará, em Fortaleza, CE ( $3^{\circ} 40^{\prime} 24^{\prime \prime S}$ e $38^{\circ} 34^{\prime} 32^{\prime \prime} \mathrm{W}$, a $12 \mathrm{~m}$ de altitude), em casa de vegetação coberta com plástico de 200 micras, tratado contra raios ultravioleta.

Em ambos os experimentos, o material testado consistiu de 20 genótipos de feijão-de-corda: 421-07-44, Chumbinho, Zebu, EPACE 10, Frade Preto, Inhumã, João Paulo II, Manteiguinha, Maranhão, Pitiúba, Quarenta Dias, Seridó, Sete Semanas, TVu 1037, TVu 1888, TVu 310, TVu 36, TVu $408 \mathrm{P}_{2}, \mathrm{TVu} 410$ e VITA 7. A semeadura foi realizada em copos descartáveis de poliestireno de $300 \mathrm{~mL}$, contendo substrato constituído de areia peneirada, húmus de minhoca e vermiculita, na proporção de $6: 3: 1$, respectivamente.

$\mathrm{O}$ primeiro ensaio, que consistiu num teste de preferência com chance de escolha, foi realizado entre 27 de julho e 31 de agosto de 2007. As temperaturas máximas e mínimas médias no local foram de $31,71^{\circ} \mathrm{C} \pm 0,63$ e $25,32^{\circ} \mathrm{C} \pm 0,67$, respectivamente. A umidade relativa máxima média foi de $77,33 \% \pm 2,24$ e a mínima média foi de $57,11 \% \pm 4,65$.

Foi utilizado o delineamento em blocos ao acaso, com 20 tratamentos e 6 repetições, em que cada unidade experimental, ou parcela, consistiu de uma planta em um copo.

Após 15 dias da semeadura, as plantas foram distribuídas sobre a bancada de maneira que não se tocassem, e foram infestadas com cinco pulgões fêmeas, adultas, ápteras e de coloração preta brilhante, provenientes da criação da própria Universidade. As repetições foram separadas em gaiolas de 1,0 $\mathrm{m}$ de largura por 1,0 $\mathrm{m}$ de comprimento e $0,50 \mathrm{~m}$ de altura e suspensas para evitar a entrada de formiga. Em cada gaiola, foram acomodados os 20 tratamentos. Após 48 horas da infestação, foram contados e retirados os pulgões adultos e, quatro dias após a infestação, foi quantificado o número de ninfas por planta sem separá-las por instar.

O teste de preferência sem chance de escolha foi realizado no segundo ensaio, entre $1^{\circ}$ de outubro e $1^{\circ}$ de novembro de 2007. As temperaturas máximas e mínimas médias no local foram de $35,20^{\circ} \mathrm{C} \pm 1,85$ e $26,30^{\circ} \mathrm{C} \pm 0,47$, respectivamente. A umidade máxima média foi de $75,70 \% \pm 1,96$ e a mínima média foi de $50,80 \% \pm 5,33$.

O delineamento utilizado foi o de blocos ao acaso com 20 tratamentos e 4 repetições. Cada parcela consistiu de uma planta em um copo. Aos 19 dias da semeadura, foi aplicado, em cada planta, $5 \mathrm{~mL}$ de solução de ureia na concentração de $0,375 \%$ de nitrogênio.

Neste ensaio, foram utilizadas minigaiolas de PVC fixadas às plantas, na região abaxial da folha, com grampos de cabelo. A minigaiola consistia de um tubo de PVC de $23 \mathrm{~mm}$ de diâmetro interno com $1 \mathrm{~cm}$ de altura, com área total de $4,15 \mathrm{~cm}^{2}$, e coberta com um tecido para permitir a circulação de ar e a entrada de luz.

Aos 21 dias após a semeadura, as gaiolas, com 5 pulgões fêmeas cada, foram fixadas na região abaxial 
de uma folha verdadeira. Após quatro dias, as gaiolas foram retiradas e quantificou-se o número de adultos vivos e mortos e de ninfas vivas.

Os dados obtidos nos dois ensaios foram transformados em $(\mathrm{x}+0,5)^{0,5}$ e submetidos à análise pelo programa Genes (Cruz, 2006). As médias dos tratamentos foram comparadas pelo teste de Scott-Knott, a $5 \%$ de probabilidade. Utilizou-se o índice de seleção de Mulamba \& Mock (1978), em que cada genótipo foi classificado, em cada uma das variáveis, na ordem do mais resistente ao mais suscetível.

\section{Resultados e Discussão}

No teste de preferência com chance de escolha, os genótipos de feijoeiro influenciaram $(\mathrm{p}<0,01)$ o número de pulgões adultos vivos, número de ninfas e a relação de ninfas/número de adultos. Os genótipos TVu 408 $\mathrm{P}_{2}$, $\mathrm{TVu} 1037$ e $\mathrm{TVu} 410$ foram preteridos pelos adultos do pulgão-preto e, juntamente com o genótipo TVu 36, apresentaram os menores números de ninfas (Tabela 1). O genótipo VITA 7, que figurou entre os suscetíveis, já havia sido descrito como tal por Messina et al. (1985).

$\mathrm{O}$ número de ninfas em relação ao número de adultos sugere a resistência da planta ao pulgão, por reduzir a capacidade de reprodução desse inseto, e essa característica foi observada em TVu $408 \mathrm{P}_{2}, \mathrm{TVu} 1037$, TVu 410, TVu 36 e EPACE 10.

Em teste sem chance de escolha, observou-se diferença estatística $(\mathrm{p}<0,01)$ entre os materiais testados, quando considerado o número de ninfas e a relação ninfas por adultos vivos de $A$. craccivora. Ao se avaliar o número de adultos vivos, a análise de variância detectou diferença significativa entre os tratamentos, a 5\% de probabilidade. Entretanto, o teste de comparação de médias (Tabela 2 ) não revelou essa diferença.

No ensaio sem chance de escolha, na avaliação do número de ninfas e da relação entre ninfas e adultos, verificou-se que os genótipos $\mathrm{TVu} 408 \mathrm{P}_{2}, \mathrm{TVu} 410$, TVu 36, TVu 1037 e Manteiguinha foram preteridos pelo pulgão, da mesma forma observada no teste com chance de escolha, com exceção do Manteiguinha. Ainda no mesmo ensaio, verificou-se que EPACE 10 foi considerado suscetível, quando se levou em conta o número de ninfas por planta, o que difere do resultado do teste com chance de escolha. Entretanto, esse material continuou resistente quando se avaliou a relação ninfas/adultos. De modo semelhante ao EPACE 10, os genótipos TVu 408P 2 , TVu 410, TVu 36, TVu 1037, Manteiguinha, Frade Preto e Pitiúba tiveram a menor relação de ninfas por adultos (Tabela 2).

A Tabela 3 foi organizada por meio do método de soma de postos, ou ranques, proposto por Mulamba \& Mock (1978). O índice de ranqueamento propiciou mais sustentação e complementou os resultados obtidos por ambos os ensaios. O teste de Scott-Knott aplicado ao ranqueamento separou os genótipos em cinco grupos, e conferiu a esses resultados rigor estatístico, como sugerem Silva et al. (2003). Os genótipos TVu 408 $\mathrm{P}_{2}$, TVu 410, TVu 36 e TVu 1037 comportaram-se como resistentes, e foram indicados para o programa de melhoramento com a finalidade de promover resistência ao pulgão-preto. Os acessos $\mathrm{TVu} 408 \mathrm{P}_{2}$ e TVu 410, em estudo realizado na Nigéria, apresentaram resistência do tipo antibiose em condições de casa de vegetação (Singh, 1977; Ofuya, 1988).

Em experimento de campo, Ofuya (1988) observou que o genótipo $\mathrm{TVu} 1037$ foi considerado como resistente por ter sido desprezado pelo pulgão, quando

Tabela 1. Número médio de adultos vivos e ninfas e relação número de ninfas/número de adultos vivos (N/Av) de Aphis craccivora, em genótipos de Vigna unguiculata, em teste com chance de escolha ${ }^{(1)}$.

\begin{tabular}{lccc}
\hline Genótipo & Adultos vivos & Ninfas & N/Av \\
\hline TVu 408P $\mathrm{P}_{2}$ & $0,50 \mathrm{a}$ & $4,33 \mathrm{a}$ & $8,67 \mathrm{a}$ \\
TVu 1037 & $0,67 \mathrm{a}$ & $6,83 \mathrm{a}$ & $10,25 \mathrm{a}$ \\
TVu 410 & $0,83 \mathrm{a}$ & $6,50 \mathrm{a}$ & $7,80 \mathrm{a}$ \\
TVu 36 & $1,33 \mathrm{~b}$ & $13,33 \mathrm{a}$ & $10,00 \mathrm{a}$ \\
EPACE 10 & $2,50 \mathrm{~b}$ & $34,50 \mathrm{~b}$ & $13,80 \mathrm{a}$ \\
Manteiguinha & $2,67 \mathrm{c}$ & $47,83 \mathrm{c}$ & $17,94 \mathrm{~b}$ \\
Inhumã & $3,67 \mathrm{c}$ & $55,33 \mathrm{c}$ & $15,09 \mathrm{~b}$ \\
TVu 1888 & $3,50 \mathrm{c}$ & $82,33 \mathrm{~d}$ & $23,52 \mathrm{~b}$ \\
Maranhão & $3,67 \mathrm{c}$ & $63,67 \mathrm{c}$ & $17,36 \mathrm{~b}$ \\
João Paulo II & $3,83 \mathrm{c}$ & $67,00 \mathrm{c}$ & $17,48 \mathrm{~b}$ \\
Frade preto & $3,83 \mathrm{c}$ & $72,00 \mathrm{~d}$ & $18,78 \mathrm{~b}$ \\
TVu 310 & $4,33 \mathrm{c}$ & $92,50 \mathrm{~d}$ & $21,35 \mathrm{~b}$ \\
Seridó & $4,33 \mathrm{c}$ & $87,50 \mathrm{~d}$ & $20,19 \mathrm{~b}$ \\
Chumbinho & $4,50 \mathrm{c}$ & $79,83 \mathrm{~d}$ & $17,74 \mathrm{~b}$ \\
Zebu & $4,67 \mathrm{c}$ & $77,50 \mathrm{~d}$ & $16,61 \mathrm{~b}$ \\
Sete semanas & $4,67 \mathrm{c}$ & $82,17 \mathrm{~d}$ & $17,61 \mathrm{~b}$ \\
Pitiúba & $4,67 \mathrm{c}$ & $99,00 \mathrm{~d}$ & $21,21 \mathrm{~b}$ \\
Quarenta Dias & $5,17 \mathrm{c}$ & $85,17 \mathrm{~d}$ & $16,48 \mathrm{~b}$ \\
421-07-44 & $5,50 \mathrm{c}$ & $106,33 \mathrm{~d}$ & $19,33 \mathrm{~b}$ \\
VITA 7 & $5,50 \mathrm{c}$ & $97,00 \mathrm{~d}$ & $17,64 \mathrm{~b}$ \\
\hline Média & 3,52 & 63,03 & 16,44 \\
CV (\%) & 19,35 & 22,26 & 29,24 \\
\hline
\end{tabular}

${ }^{(1)}$ Médias com letras iguais não diferem entre si pelo teste de Scott-Knott a $5 \%$ de probabilidade. 
comparado a outros materiais. Ao se observar os grupos dos genótipos resistentes, o TVu $408 \mathrm{P}_{2}$ se destacou por sempre apresentar a menor posição no ranque, no que se refere às sete variáveis analisadas. Um segundo grupo, formado pelos genótipos Manteiguinha e EPACE 10, apresentou resistência intermediária. O genótipo 421-07-44 destacou-se, de forma isolada, como suscetível, e se diferenciou estatisticamente dos demais genótipos.

O genótipo EPACE 10 é proveniente da linha CNCx166-8E obtida a partir do cruzamento entre TVu 1888 e a cultivar Seridó. Observou-se que ambos os genitores foram suscetíveis, em todas as variáveis avaliadas, enquanto o EPACE 10 foi moderadamente resistente. Entre os fatores que explicam este efeito, pode-se citar a combinação gênica favorável à resistência a $A$. craccivora resultante da combinação dos genes dos dois pais. Outro motivo seria a ocorrência da epistasia, em que um gene inibe a expressão do outro (Ramalho et al., 2004). Os genes

Tabela 2. Número médio de adultos vivos, de adultos mortos e de ninfas, e relação número de ninfas/número de adulto vivos (N/Av) de Aphis craccivora, em genótipos de Vigna unguiculata, em teste sem chance de escolha ${ }^{(1)}$.

\begin{tabular}{lccrr}
\hline Genótipo & Adultos vivos & Adultos mortos & Ninfas & N/Av \\
\hline TVu 408P2 & $0,00 \mathrm{a}$ & $5,00 \mathrm{a}$ & $0,00 \mathrm{a}$ & $0,00 \mathrm{a}$ \\
TVu 410 & $0,00 \mathrm{a}$ & $5,00 \mathrm{a}$ & $0,00 \mathrm{a}$ & $0,00 \mathrm{a}$ \\
TVu 36 & $0,25 \mathrm{a}$ & $4,75 \mathrm{a}$ & $2,75 \mathrm{a}$ & $11,00 \mathrm{a}$ \\
Manteiguinha & $1,00 \mathrm{a}$ & $4,00 \mathrm{a}$ & $18,00 \mathrm{a}$ & $18,00 \mathrm{a}$ \\
TVu 1037 & $1,50 \mathrm{a}$ & $3,50 \mathrm{a}$ & $23,00 \mathrm{a}$ & $15,33 \mathrm{a}$ \\
Frade preto & $1,75 \mathrm{a}$ & $3,25 \mathrm{a}$ & $31,25 \mathrm{~b}$ & $17,86 \mathrm{a}$ \\
TVu 1888 & $1,50 \mathrm{a}$ & $3,50 \mathrm{a}$ & $46,50 \mathrm{~b}$ & $31,00 \mathrm{~b}$ \\
VITA 7 & $1,75 \mathrm{a}$ & $3,25 \mathrm{a}$ & $38,25 \mathrm{~b}$ & $21,86 \mathrm{~b}$ \\
Pitiúba & $2,25 \mathrm{a}$ & $2,75 \mathrm{a}$ & $56,75 \mathrm{~b}$ & $25,22 \mathrm{a}$ \\
EPACE 10 & $2,50 \mathrm{a}$ & $2,50 \mathrm{a}$ & $39,75 \mathrm{~b}$ & $15,90 \mathrm{a}$ \\
Quarenta Dias & $2,25 \mathrm{a}$ & $2,75 \mathrm{a}$ & $34,00 \mathrm{~b}$ & $15,11 \mathrm{~b}$ \\
Chumbinho & 2,50 & $2,50 \mathrm{a}$ & $56,75 \mathrm{~b}$ & $22,70 \mathrm{~b}$ \\
Seridó & $2,75 \mathrm{a}$ & $2,25 \mathrm{a}$ & $56,00 \mathrm{~b}$ & $20,36 \mathrm{~b}$ \\
Maranhão & $2,75 \mathrm{a}$ & $2,25 \mathrm{a}$ & $49,75 \mathrm{~b}$ & $18,09 \mathrm{~b}$ \\
Zebu & $2,75 \mathrm{a}$ & $2,25 \mathrm{a}$ & $71,50 \mathrm{~b}$ & $26,00 \mathrm{~b}$ \\
TVu 310 & $3,25 \mathrm{a}$ & $1,75 \mathrm{a}$ & $67,25 \mathrm{~b}$ & $20,69 \mathrm{~b}$ \\
Inhumã & $3,50 \mathrm{a}$ & $1,50 \mathrm{a}$ & $73,25 \mathrm{~b}$ & $20,93 \mathrm{~b}$ \\
Sete semanas & $3,25 \mathrm{a}$ & $1,75 \mathrm{a}$ & $60,00 \mathrm{~b}$ & $18,46 \mathrm{~b}$ \\
João Paulo II & $3,75 \mathrm{a}$ & $1,25 \mathrm{a}$ & $54,25 \mathrm{~b}$ & $14,47 \mathrm{~b}$ \\
421-07-44 & $4,25 \mathrm{a}$ & $0,75 \mathrm{a}$ & $101,50 \mathrm{~b}$ & $23,88 \mathrm{~b}$ \\
\hline Média & 2,18 & 2,83 & 44,03 & 17,84 \\
CV (\%) & 40,44 & 35,39 & 52,39 & 50,59 \\
\hline
\end{tabular}

${ }^{(1)}$ Médias seguidas por letras iguais não diferem entre si pelo teste de Scott-Knott, a 5\% de probabilidade. de resistência, neste caso, estariam sendo inibidos nos pais que, por isso, não teriam demonstrado essa característica. Entretanto, quando foram cruzados os genótipos, os genes da resistência podem ter deixado de ser hipostásticos no EPACE 10.

Por sua vez, a cultivar João Paulo II, resultante do cruzamento entre CE 315 e 'Seridó', tem um parental comum com EPACE 10. De maneira similar ao que se verificou com 'Seridó', 'João Paulo II' continuou suscetível ao pulgão, e não diferiu estatisticamente deste. A combinação gênica do 'Seridó' com o CE 315 provavelmente não resultou em uma combinação favorável para a resistência, ou não desfez algum efeito epistático como pode ter ocorrido no EPACE 10, embora não tenha ficado certo se realmente a resistência adquirida pelo EPACE 10 foi herdada exclusivamente do genótipo Seridó.

O TVu 310 é descrito como resistente por Singh (1987) na Nigéria, mas no presente experimento apresentou-se como suscetível na análise estatística. Fato semelhante ocorreu com o $\mathrm{TVu} 3000$, que foi relatado como resistente no oeste da África e suscetível no sul da Geórgia, Estados Unidos, sendo os genótipos locais considerados mais resistentes, o que demonstra, assim, o efeito da interação genótipo/ambiente sobre a resistência do genótipo de feijão-de-corda ao pulgão (Messina et al., 1985).

Outro motivo para a mudança de comportamento do genótipo TVu 310 provavelmente é a existência de biótipos de $A$. craccivora. Estudos relatados por Moraes \& Bleicher(2007) indicam a existência de pelo menos cinco biótipos de pulgão-preto-do-feijoeiro. Assim, é possível que este genótipo não seja resistente ao biótipo utilizado no presente experimento.

O genótipo Inhumã alcançou ótimas classificações no experimento com chance de escolha, e o oposto foi observado no experimento sem chance de escolha. Esse resultado pode ter sido resultante de sinais químicos de repelência, emitidos pelas plantas para evitar o ataque de insetos (Pickett et al., 2005), o que teria provocado baixa infestação, no experimento com chance de escolha. Entretanto, quando os insetos foram obrigados a permanecer na planta, esses sinais não teriam impedido o desenvolvimento dos insetos. Sendo assim, é provável que a resistência de 'Inhumã' seja do tipo antixenose (não preferência). Esse resultado também demonstra a importância do teste sem chance de escolha, uma vez que um 
Tabela 3. Classificação de preferência de Aphis craccivora por genótipos de Vigna unguiculata, em testes com e sem chance de escolha ${ }^{(1)}$.

\begin{tabular}{|c|c|c|c|c|c|c|c|c|c|}
\hline \multirow[t]{2}{*}{ Ranque } & \multirow[t]{2}{*}{ Genótipo } & \multicolumn{4}{|c|}{ Sem chance de escolha } & \multicolumn{3}{|c|}{ Com chance de escolha } & \multirow[t]{2}{*}{ Soma } \\
\hline & & Adultos vivos & Adultos mortos & Ninfas & $\mathrm{N} / \mathrm{Av}$ & Adultos vivos & Ninfas & $\mathrm{N} / \mathrm{Av}$ & \\
\hline 1 & $\mathrm{TVu} 408 \mathrm{P}_{2}$ & 1 & 1 & 1 & 1 & 1 & 1 & 1 & $7 \mathrm{a}$ \\
\hline 2 & TVu 410 & 2 & 2 & 2 & 2 & 3 & 2 & 2 & $15 \mathrm{a}$ \\
\hline 3 & TVu 36 & 3 & 3 & 3 & 3 & 4 & 4 & 4 & $24 \mathrm{a}$ \\
\hline 4 & TVu 1037 & 5 & 7 & 4 & 5 & 2 & 3 & 3 & $29 a$ \\
\hline 5 & Manteiguinha & 4 & 4 & 5 & 4 & 6 & 6 & 17 & $46 b$ \\
\hline 6 & EPACE 10 & 10 & 14 & 6 & 7 & 5 & 5 & 5 & $52 \mathrm{~b}$ \\
\hline 7 & Frade preto & 6 & 8 & 7 & 6 & 11 & 10 & 15 & $63 c$ \\
\hline 8 & Maranhão & 14 & 13 & 10 & 10 & 9 & 8 & 10 & $74 \mathrm{c}$ \\
\hline 9 & Quarenta Dias & 11 & 9 & 8 & 9 & 18 & 16 & 8 & $79 \mathrm{c}$ \\
\hline 10 & Chumbinho & 12 & 10 & 12 & 13 & 14 & 12 & 13 & $86 \mathrm{c}$ \\
\hline 11 & Inhumã & 17 & 19 & 18 & 12 & 7 & 7 & 6 & $86 \mathrm{c}$ \\
\hline 12 & TVu 1888 & 7 & 5 & 13 & 20 & 8 & 14 & 20 & $87 \mathrm{c}$ \\
\hline 13 & VITA 7 & 8 & 6 & 9 & 17 & 20 & 18 & 9 & $87 \mathrm{c}$ \\
\hline 14 & Pitiúba & 9 & 11 & 11 & 8 & 17 & 19 & 18 & $93 c$ \\
\hline 15 & Zebu & 15 & 12 & 19 & 19 & 15 & 11 & 7 & $98 \mathrm{~d}$ \\
\hline 16 & Seridó & 13 & 15 & 14 & 16 & 13 & 13 & 14 & $98 \mathrm{~d}$ \\
\hline 17 & João Paulo II & 19 & 18 & 17 & 15 & 10 & 9 & 11 & $99 d$ \\
\hline 18 & Sete semanas & 18 & 16 & 15 & 14 & 16 & 15 & 12 & $106 \mathrm{~d}$ \\
\hline 19 & TVu 310 & 16 & 17 & 16 & 11 & 12 & 17 & 19 & $108 \mathrm{~d}$ \\
\hline 20 & $421-07-44$ & 20 & 20 & 20 & 18 & 19 & 20 & 16 & $133 \mathrm{e}$ \\
\hline
\end{tabular}

${ }^{(1)}$ Somas seguidas por letras iguais não diferem entre si pelo teste de Scott-Knott a 5\% de probabilidade. N/Av, relação entre número de ninfas e número de adultos vivos.

genótipo preterido, em condições de livre escolha, pode tornar-se suscetível quando o inseto não tem hospedeiro alternativo.

Genótipos como o TVu 408 $\mathrm{P}_{2}$, TVu 410, TVu 36 e $\mathrm{TVu}$ 1037, no grupo dos resistentes, e Sete Semanas, $\mathrm{TVu} 310$ e 421-07-44, no grupo dos suscetíveis, apresentaram ranques semelhantes. A escolha de materiais com comportamento semelhante nos dois tipos de experimentos é importante para se alcançar resultados mais homogêneos nas comparações em experimentos posteriores, principalmente no que se refere à ação de produtos de indução de resistência de plantas a insetos.

\section{Conclusões}

1. Os genótipos estudados apresentaram variabilidade genética em relação à susceptibilidade a Aphis craccivora.

2. Os genótipos $\mathrm{TVu} 408 \mathrm{P}_{2}, \mathrm{TVu} 410, \mathrm{TVu} 36$ e $\mathrm{TVu} 1037$ apresentam maior resistência natural.

3. Os mecanismos de resistência apresentados pelos genótipos TVu 408P $\mathrm{P}_{2}$, TVu 410, TVu 36 e TVu 1037 são do tipo antibiose e antixenose.
4. O genótipo 421-07-44 não afeta a população a A. craccivora.

\section{Referências}

AGELE, S.O.; OFUYA, T.I.; JAMES, P.O. Effects of watering regimes on aphid infestation and performance of selected varieties of cowpea (Vigna unguiculata L. Walp) in a humid rainforest zone of Nigeria. Crop Protection, v.25, p.73-78, 2006.

BERBERET, R.C.; GILES, K.L.; ZARRABI, A.A.; PAYTON, M.E. Development, reproduction, and within-plant infestation patterns of Aphis craccivora (Homoptera: Aphididae) on Alfalfa. Environmental Entomology, v.38, p.1765-1771, 2009.

CRUZ, C.D. Programa Genes: estatística experimental e matrizes. Viçosa: UFV, 2006. 285p.

DAS, B.C.; SARKER, P.K.; RAHMAN, M.M. Aphidicidal activity of some indigenous plant extracts against bean aphid Aphis craccivora Koch (Homoptera: Aphididae). Journal of Pest Science, v.81, p.153-159, 2008.

FREIRE FILHO, F.R.; LIMA, J.A. de A.; RIBEIRO, V.Q. (Ed.). Feijão-caupi: avanços tecnológicos. Brasília: Embrapa Informação Tecnológica; Teresina: Embrapa Meio Norte, 2005. 519p.

HALL, A.E.; CISSE, N.; THIAW, S.; ELAWAD, H.O.A.; EHLERS, J.D.; ISMAIL, A.M.; FERY, R.L.; ROBERTS, P.A.; KITCH, L.W.; MURDOCK, L.L.; BOUKAR, O.; PHILLIPS, R.D.; MCWATTERS, K.H. Development of cowpea cultivars and 
germplasm by the Bean/Cowpea CRSP. Field Crops Research, v.82, p.103-134, 2003.

KITAJIMA, E.W.; ALCÂNTARA, B.K. de; MADUREIRA, P.M.; ALFENAS-ZERBINI, P. REZENDE, J.A.M.; ZERBINI, F.M. A mosaic of beach bean (Canavalia rosea) caused by an isolate of Cowpea aphid-borne mosaic virus (CABMV) in Brazil. Archives of Virology, v. 153, p.743-747, 2008.

MESSINA, F.J.; RENWICK, J.A.A.; BARMORE, J.L. Resistance to Aphis craccivora (Homoptera: Aphididae) in selected varieties of cowpea. Journal of Entomological Science, v.20, p.263-269, 1985.

MORAES, J.G.L.; BLEICHER, E. Preferência do pulgão-preto, Aphis craccivora Koch, a diferentes genótipos de feijão-de-corda, Vigna unguiculata (L.) Walp. Ciência Rural, v.37, p.1554-1557, 2007.

MULAMBA, N.N.; MOCK, J.J. Improvement of yield potential of Eto Blanco maize (Zea mays L.) population by breeding for plant traits. Egyptian Journal of Genetics and Cytology, v.7, p.40-51, 1978.

OFUYA, T.I. Varietal resistance of cowpeas to the cowpea aphid, Aphis craccivora Kock (Homoptera: Aphididae) under field and screenhouse conditions in Nigeria. Tropical Pest Management, v.34, p.445-447, 1988.

OMKAR; MISHRA, G.; SRIVASTAVA, S.; GUPTA, A.K.; SINGH, S.K. Reproductive performance of four aphidophagous ladybirds on cowpea aphid, Aphis craccivora Koch. Journal of Applied Entomology, v.129, p.217-220, 2005.

PETTERSSON, J.; KARUNARATNE, S.; AHMED, E.; KUMAR, V. The cowpea aphid, Aphis craccivora, host plant odours and pheromones. Entomologia Experimentalis et Applicata, v.88, p.177-184, 1998.

PICKETT, J.A.; BIRKETT, M.A.; BRUCE, T.J.A.; CHAMBERLAIN, K.; GORDON-WEEKS, R.; MATTHES, M.C.;
MORAES, C.B.; NAPIER, J.A.; SMART, L.E.; WADHAMS, L.J.; WOODCOCK, C.M. cis-Jasmone as an allelopathic agent through plant defence induction. Pesticide Outlook, v.14, p.96-98, 2005.

RAKHSHANI, E.; TALEBI, A.A.; KAVALLIERATOS, N.G.; REZWANI, A.; MANZARI, S.; TOMANOVIC, Z. Parasitoid complex (Hymenoptera, Braconidae, Aphidiinae) of Aphis craccivora Koch (Hemiptera: Aphidoidea) in Iran. Journal of Pest Science, v.78, p.193-198, 2005.

RAMALHO, M.A.P.; SANTOS, J.B.; PINTO, C.A.B.P. Genética na agropecuária. 3.ed. Lavras: UFLA, 2004. 472p.

SILVA, L.A.; PINTO, C.A.B.P.; LAMBERT, E.S. Seleção simultânea para vários caracteres: utilização do índice de Mulamba e Mock associado ao teste de Scott-Knott. In: SIMPÓSIO DE ESTATÍSTICA APLICADA À EXPERIMENTAÇÃO AGRONÔMICA, 10; REUNIÃO ANUAL DA REGIÃO BRASILEIRA DA SOCIEDADE INTERNACIONAL DE BIOMETRIA, 48., 2003, Lavras. Anais. Lavras: Universidade Federal de Lavras, 2003. p.395-400.

SILVA, P.H.S.; CARNEIRO, J.S.; QUINDERÉ, M.A.W. Pragas. In: FREIRE FILHO, F.R.; LIMA, J.A. de A.; RIBEIRO, V.Q. (Ed.) Feijão-caupi: avanços tecnológicos. Brasília: Embrapa Informação Tecnológica; Teresina: Embrapa Meio Norte, 2005. p.369-402.

SINGH, S.R. Cowpea cultivars resistant to insect pests in world germplasm collection. Tropical Grain Legume Bulletin, v.9, p.3-7, 1977.

SINGH, S.R. Host plant resistance for cowpea insect pest management. Insect Science and its Application, v.8, p.765-769, 1987.

TEÓFILO, E.M.; DUTRA, A.S.; PITOMBEIRA, J.B.; DIAS, F.T.C.; BARBOSA, F. de S. Potencial fisiológico de sementes de feijão caupi produzidas em duas regiões do Estado do Ceará. Revista Ciência Agronômica, v.39, p.443-448, 2008.

Recebido em 29 de abril de 2010 e aprovado em 3 de setembro de 2010 